\title{
Vitamin D, Inflammatory Markers, Steroid Use and Systemic Factors: which Is the Culprit in Rheumatoid Arthritis Associated Osteoporosis?

\section{Abstract}

Aim: To explore the risk factors for osteoporosis in Rheumatoid Arthritis (RA) patients.

Methods: A cross-sectional study was conducted on 93 patients meeting the American College of Rheumatology - European League Against Rheumatism classification criteria for RA 2010(ACR-EULAR). Serum $25-\mathrm{OH}$ vitamin D $(25(\mathrm{OH})$ D levels was measured. In addition, the levels of erythrocyte sedimentation rate (ESR) and C-reactive protein (CRP), rheumatoid factor (RhF), anticyclic - citrullinated protein/peptide antibodies (Anti-CCP) were assessed. Dual-energy X-ray absorptiometry (DEXA) was also used to measure the bone mineral density BMD of the left femur at the time of recruitment.

Results: The RA cohort was predominantly female (88.2\%). The average age of the participants was $46.5 \pm 15.2$ years. Osteoporosis was present in 25 (26.9\%). Osteoporotic cases were significantly older $(p<0.001)$, female $(p=0.032)$ and had significantly more frequencies of diabetes $(p=0.022)$ and hypertension $(p=0.018)$ and had significantly lower calcium ( $p=0.038$ ). Logistic regression model for factors affecting osteoporosis showed that Steroids intake, increasing age and decreasing serum calcium were factors increasing the likelihood of having osteoporosis. Vitamin D did not show any relation with osteoporosis. Serum inflammatory markers like ESR, CRP, R.F and anti- CCP were higher in osteoporotic group but not significant.

Conclusions: The results of this analysis indicated that systemic factors like age and intake of steroids are culprit factors in rheumatoid arthritis associated osteoporosis.
Sahar Saad1,

Khalid A AbulSaad², Safaa Hussein Ali²

1 Rheumatology and rehabilitation department, Faculty of Medicine, Assiut University, Cairo, Egypt.

2 Geriatrics and Gerontology department, Faculty of Medicine, Ain Shams University, Cairo, Egypt.

Contact information:

Safaa Hussein Ali.

MD, Geriatrics and Gerontology department, Faculty of Medicine.

Address: Ain Shams University, Abbassia district, Ramsis street, Cairo, Egypt. http://med.shams.edu.eg/

Tel: 00201067150707

झ bokabokloz@yahoo.com

\section{Keywords}

Osteoporosis; Rheumatoid

Arthritis; Vitamin D;

Comorbidities. 


\section{Introduction}

Rheumatoid arthritis (RA) is a chronic inflammatory multisystemic disease targeting the synovium [1]. The condition exists worldwide and affects all ethnic groups at a rate of approximately $0.5 \%$ to $1 \%$ of the adult population [2].

RA is associated with reduced bone density $[3,4]$ and an increased risk of fragility fractures [5]. The pathophysiology of osteoporosis is complex, with contributions from general risk factors such as age, low body weight and postmenopausal status, along with disease-specific risk factors such as decreased mobility, corticosteroid use and production of proinflammatory cytokines [6, 7].

In fact, a lower dietary intake of vitamin $D$ has been linked to a higher risk of RA development in a meta-analysis of several studies [9]; furthermore, plasma $25(\mathrm{OH})$ D concentrations has been reported to be lower in RA patients when compared to healthy control [10] although these results were not confirmed in other studies [11]. Vitamin D has also been inversely correlated with disease activity [9, 12].

The importance of inflammatory disease as a pathogenic factor is emphasized by the fact that there is a positive correlation between disease activity and biochemical markers of bone resorption in RA [6].

One other major factor in the pathogenesis of osteoporosis in rheumatic diseases is the long term use of corticosteroids. It is known that glucocorticoids can induce osteoporosis through different mechanisms [13] in fact, the use of glucocorticoids reduces the number and the function of osteoblasts[14] and impairs their differentiation and maturation [15] In the clinical setting glucocorticoid treatment is an independent risk factor for bone loss [16]; According to ACR guidelines, any patient starting a long term (>3 months) steroid regimen should receive calcium and vitamin D; furthermore, bisphosphonates should be started according to the assessed osteoporosis risk [17].
It is increasingly recognized that comorbid conditions play a pivotal role in RA outcomes. Studies reveal that patients suffering from RA carry two or more comorbid conditions [18]. Linde and his colleagues [19] demonstrated a 73\% incidence of comorbidities associated with RA.

The aim of the current study is to reveal the association between osteoporosis and RA factors associated with osteoporosis among RA patients. This study targeted RA specific factors (corticosteroid use and inflammatory markers) and general risk factors (comorbidities and vitamin D).

\section{Methodology}

\section{Ethics}

Each patient gave written informed consent and the study was approved by the local ethics committee.

\section{Study design}

This is a cross-sectional study.

\section{Patient Selection}

From October 2013 to September 2014, 93 Participants were selected from known RA patients referred to the rheumatology clinics of a tertiary center. Patients were diagnosed with RA by a rheumatologist based on the American College of Rheumatology -European League against Rheumatism (ACR-EULAR)

Classification criteria. Physical conditions and medical history of all the patients were obtained [20].

\section{Sample size}

The estimated sample size was, based on a $1 \%$ prevalence of rheumatoid arthritis in the general population, standard error of $1.5 \%$ and type $1(\alpha)$ error of 0.05 [2]

\section{Data Collection}

Extensive demographic and clinical data were also collected at this time including comorbidities. Infor- 
mation was collected on the following co-morbidities: cardiovascular disease, respiratory disease, cerebrovascular diseases, neurological disease, chronic renal and liver impairment, gastrointestinal disease, diabetes, thyroid disease and cancer.

Dual-energy X-ray absorptiometry (DEXA, QDR4500; Hologic, Inc., Bedford, MA, USA) was used to measure the BMD of the left femoral neck at the time of recruitment. The patients with $T$ scores higher than -1.0 were considered to have normal $B M D$, those with a $T$ score lower than -2.5 were considered to have osteoporosis [3].

Laboratory data includes; Serum 25-hydroxyvitamin D (250HD) was measured using radioimmunoassay (Elecsys, Roche, Basel, Switzerland)/ with a DiaSorin kit (DiaSorin Ltd., Dartford, UK)/ was checked using Roch kits (Germany). Erythrocyte sedimentation rate (ESR) and C-reactive protein (CRP) were considered to be markers of inflammatory activity. C-reactive protein (CRP: $\mathrm{mg} / \mathrm{dL}$ ) was assessed using a quantitative method called turbidimetry and ESR ( $\mathrm{mm} / \mathrm{h})$ was measured by the Westegren method. Rheumatoid factor (RF immunoglobulin $G$ [lgG], IU/mL) was determined by the immunoturbidimetric method and RF > $14 \mathrm{lU} / \mathrm{mL}$ was defined as positive. Anti-cyclic citrulinated peptide (anti-CCP $\lg \mathrm{G}, \mathrm{IU} / \mathrm{mL}$ ) was determined by the enzyme-linked immunosorbent assay (ELISA) method and anti-CCP $>5 \mathrm{lU} / \mathrm{mL}$ was defined as positive. CA also was registered. (DADE Dimension Rx1 full-automatic biochemical analyzer).

\section{Exclusion criteria}

Patients with symptoms of RA that were overlapped by other rheumatologic disnease (overlap syndrome), patients with abnormal calcium and phosphorus and end-stage renal disease. Current cancer, endocrine abnormalities (hyperthyroidism, hyperparathyroidism), moderate-severe chronic kidney disease (glomerular filtration rate $<60 \mathrm{~mL} / \mathrm{min} / 1.73$ $\left.m^{2}\right)$.

\section{Comparison Groups}

The RA cohort group was divided to osteoporotic and non-osteoporotic group by measuring BMD. Those with a $\mathrm{T}$ score lower than -2.5 were considered to have osteoporosis [21].

\section{Statistical Methods}

The collected data were coded, tabulated, and statistically analyzed using IBM SPSS statistics (Statistical Package for Social Sciences) software version 22.0, IBM Corp., Chicago, USA, 2013. Descriptive statistics were done for quantitative data as minimum\& maximum of the range as well as mean \pm SD (standard deviation) for quantitative parametric data, while it was done for qualitative data as number and percentage. Inferential analyses were done for quantitative variables using independent t-test in cases of two independent groups with parametric data and Chi square test for differences between proportions. Logistic regression model was used to find out independent factors affecting osteoporosis. ROC curve was used to evaluate the performance of different tests differentiate between osteoporotic and non-osteoporotic cases. The level of significance was taken at $P$ value $<0.05$ is significant, otherwise is non-significant.

\section{Results}

The demographic and clinical characteristics (mean \pm standard deviation) of the 93 patients are reported in table 1. The mean age of the study population was $46.5 \pm 15.2$ years. 82 (88.2\%) were female. Of the study group, $65.6 \%$ were rheumatoid factor positive, $22.6 \%$ were taking steroids, $17.2 \%$ were diabetics and $14.0 \%$ were hypertensive.

Osteoporotic cases were $26.9 \%$ of our study group. Osteoporotic cases were significantly older (60.6 years), $(p<0.001)$, female $(p=0.032)$, had significantly more frequencies of diabetes $(p=0.022)$, hypertension ( $p=0.018$ ) and had significantly lower calcium ( $p=0.038$ ). Steroid intake was not signifi- 
Table 1. Distribution of the domains and facets of QoL. João Pessoa, PB, 2015.

\begin{tabular}{|c|c|c|c|c|c|c|}
\hline \multicolumn{2}{|c|}{ Variables } & $\begin{array}{l}\text { All cases } \\
(\mathrm{N}=93)\end{array}$ & $\begin{array}{l}\text { Osteoporosis } \\
\qquad(N=25)\end{array}$ & $\begin{array}{l}\text { No osteopor } \\
\quad(N=68)\end{array}$ & $\mathbf{P}$ & $\begin{array}{c}\text { OR } \\
(95 \% \mathrm{Cl})\end{array}$ \\
\hline \multicolumn{2}{|c|}{ Osteoporosis } & 25 (26.9\%) & -- & -- & -- & -- \\
\hline \multirow{2}{*}{ Age (years) } & Mean \pm SD & $46.5 \pm 15.2$ & $60.6 \pm 9.3$ & $41.4 \pm 13.6$ & \multirow{2}{*}{$\stackrel{\wedge}{\wedge} \hat{0.001 *}^{*}$} & \multirow{2}{*}{--} \\
\hline & Range & $16.0-83.0$ & $42.0-83.0$ & $16.0-80.0$ & & \\
\hline \multirow{2}{*}{ Sex } & Male & $11(11.8 \%)$ & $0(0.0 \%)$ & $11(16.2 \%)$ & \multirow{2}{*}{$\begin{array}{c}\# \\
0.032^{*}\end{array}$} & \multirow{2}{*}{--} \\
\hline & Female & 82 (88.2\%) & 25 (100.0\%) & 57 (83.8\%) & & \\
\hline \multirow{2}{*}{ Diagnosis } & Sero +ve & $61(65.6 \%)$ & $19(76.0 \%)$ & $42(61.8 \%)$ & \multirow{2}{*}{$\begin{array}{c}\# \\
0.200\end{array}$} & \multirow{2}{*}{$\begin{array}{c}1.96 \\
(0.69-5.55)\end{array}$} \\
\hline & Sero -ve & 32 (34.4\%) & $6(24.0 \%)$ & $26(38.2 \%)$ & & \\
\hline \multicolumn{2}{|c|}{ DM } & $16(17.2 \%)$ & $8(32.0 \%)$ & $8(11.8 \%)$ & $\begin{array}{c}\# \\
0.022^{*}\end{array}$ & $\begin{array}{c}3.53 \\
(1.54-10.8)\end{array}$ \\
\hline \multicolumn{2}{|c|}{ HTN } & $13(14.0 \%)$ & 7 (28.0\%) & $6(8.8 \%)$ & $\begin{array}{c}\# \\
0.018^{*}\end{array}$ & $\begin{array}{c}4.02 \\
(1.19-13.5)\end{array}$ \\
\hline \multicolumn{2}{|c|}{ Thyroid disease } & $4(4.3 \%)$ & $1(4.0 \%)$ & $3(4.4 \%)$ & $\begin{array}{c}\# \\
0.931\end{array}$ & $\begin{array}{c}0.90 \\
(0.09-9.0)\end{array}$ \\
\hline \multicolumn{2}{|c|}{ Steroids intake } & $21(22.6 \%)$ & $9(36.0 \%)$ & $12(17.6 \%)$ & $\begin{array}{c}\# \\
0.061\end{array}$ & $\begin{array}{c}2.61 \\
(0.94-7.33)\end{array}$ \\
\hline
\end{tabular}

^Independent t-test, \#Chi square test, *Significant, OR: Odd ratio, Cl: Confidence interval. DM = diabetes, HTN= hypertension

Table 2. Laboratory findings among the studied cases

\begin{tabular}{|c|c|c|c|c|c|c|}
\hline \multicolumn{2}{|c|}{ Variables } & $\begin{array}{l}\text { All cases } \\
(\mathrm{N}=93)\end{array}$ & $\begin{array}{l}\text { Osteoporosis } \\
\qquad(N=25)\end{array}$ & $\begin{array}{l}\text { No osteopor } \\
(N=68)\end{array}$ & $\mathbf{P}$ & $\begin{array}{c}\text { OR } \\
(95 \% \mathrm{Cl})\end{array}$ \\
\hline \multirow{2}{*}{$\begin{array}{l}\text { Vitamin-D } \\
\mathrm{ng} / \mathrm{ml}\end{array}$} & Mean $\pm S D$ & $9.1 \pm 3.5$ & $10.0 \pm 2.9$ & $8.8 \pm 3.6$ & \multirow{2}{*}{$\hat{\wedge}$} & \multirow{2}{*}{-- } \\
\hline & Range & $3.1-15.0$ & $4.5-14.6$ & $3.1-15.0$ & & \\
\hline \multirow{2}{*}{$\begin{array}{l}\text { Serum Ca } \\
\mathrm{mg} / \mathrm{dL}\end{array}$} & Mean \pm SD & $2.23 \pm 0.14$ & $2.18 \pm 0.16$ & $2.25 \pm 0.13$ & \multirow{2}{*}{$\hat{\wedge} .038$} & \multirow{2}{*}{-- } \\
\hline & Range & $1.82-2.47$ & $1.82-2.40$ & $2.0-2.47$ & & \\
\hline \multirow{2}{*}{$\begin{array}{l}\text { Hemoglobin } \\
\text { g/DI }\end{array}$} & Mean \pm SD & $12.5 \pm 2.2$ & $12.6 \pm 1.8$ & $12.4 \pm 2.3$ & \multirow{2}{*}{$\hat{\wedge} \hat{0}$} & \multirow{2}{*}{-- } \\
\hline & Range & $9.0-27.0$ & $9.0-15.6$ & $9.2-27.0$ & & \\
\hline \multirow{2}{*}{$\begin{array}{l}\mathrm{ESR} \\
\mathrm{mm} / \mathrm{hr}\end{array}$} & Mean \pm SD & $49.9 \pm 26.1$ & $56.8 \pm 31.3$ & $47.1 \pm 23.4$ & \multirow{2}{*}{$\hat{\wedge}$} & \multirow{2}{*}{-- } \\
\hline & Range & $2.0-120.0$ & $18.0-120.0$ & 2.0-109.0 & & \\
\hline \multirow{2}{*}{$\begin{array}{l}\text { CRP } \\
\mathrm{mg} / \mathrm{dL}\end{array}$} & Mean \pm SD & $15.3 \pm 16.8$ & $17.0 \pm 19.1$ & $14.7 \pm 16.1$ & $\wedge$ & \multirow[t]{2}{*}{--} \\
\hline & Range & $0.0-81.7$ & $0.7-72.8$ & $0.0-81.7$ & 0.573 & \\
\hline \multirow{2}{*}{$\begin{array}{l}\text { Anti-CCP } \\
\text { IU/mL }\end{array}$} & Mean $\pm S D$ & $613.1 \pm 1213.6$ & $869.0 \pm 1844.4$ & $512.8 \pm 855.9$ & \multirow{2}{*}{$\hat{\wedge} .269$} & \multirow[t]{2}{*}{--} \\
\hline & Range & $0.0-7800.0$ & $0.3-7800.0$ & $0.0-3900.0$ & & \\
\hline \multicolumn{2}{|l|}{ Positive ANA } & $10(10.8 \%)$ & $2(8.0 \%)$ & $8(11.8 \%)$ & $\begin{array}{c}\# \\
0.603\end{array}$ & $\begin{array}{c}0.65 \\
(0.13-3.30)\end{array}$ \\
\hline \multicolumn{2}{|l|}{ Positive RF } & $71(76.3 \%)$ & 19 (76.0\%) & $52(76.5 \%)$ & $\begin{array}{c}\# \\
0.962\end{array}$ & $\begin{array}{c}0.37 \\
(0.15-0.87)\end{array}$ \\
\hline
\end{tabular}

Andependent t-test, \#Chi square test, ${ }^{*}$ Significant, OR: Odd ratio, Cl: Confidence interval 
cant in univariate analysis between the osteoporotic and none ( $P \geq 0.05)$.

Table 2 reveals that all rheumatoid patients have low vitamin $D(9.1 \pm 3.5 \mathrm{mg} / \mathrm{ml})$, normal calcium and hemoglobin level $(2.23 \pm 0.14$ and $12.5 \pm 2.2$ respectively), high ESR (49.9 \pm 26.1) and high CRP (15.3 \pm 16.8). Anti CCP was high (613.1 \pm 1213.6$)$ also.

Among the biochemical parameters (table 2), the mean serum ionized calcium was significantly lower in the osteoporotic group than in the normal group, despite remaining within the normal range $(P=0.038)$.

Table $\mathbf{2}$ also shows that Inflammatory markers were higher in osteoporotic group but did not reach statistical significance between the osteoporotic and non-osteoporotic (ESR, CRP, positive RF and anti$C C P)(P \geq 0.5)$. No statistically significant differences were found in mean vitamin $D$ level between the osteoporotic and none ( $P \geq 0.5)$.

Table 3 presents the multiple linear regression models for factors affecting total femur BMD. Adjustments for possible interactions and potential confounders were made for demographics, vitamin $D$, calcium intake, inflammatory markers and corticosteroid use. It was found that the only independent predictors of osteoporosis were age (OR 1.164, 95\% Cl 1.084-1.249) and Steroids intake (OR $3.745,95 \% \mathrm{Cl} 0.889-15.773)$. Low serum calcium was also considered to be negative risk factors for lower BMD (OR 0.016, 95\% Cl 0.003-0.101).

Table 3. Logistic regression model for factors affecting osteoporosis.

\begin{tabular}{|l|c|c|c|c|}
\hline Factors & B & SE & $\mathbf{P}$ & $95 \%$ Cl \\
\hline Age & 0.152 & 0.036 & $<0.001 *$ & $\begin{array}{c}1.164 \\
(1.084-1.249)\end{array}$ \\
\hline Steroids & 1.320 & 0.734 & 0.072 & $\begin{array}{c}3.745 \\
(0.889-15.773)\end{array}$ \\
\hline Serum Ca & -4.114 & 0.932 & $<0.001 *$ & $\begin{array}{c}0.016 \\
(0.003-0.101)\end{array}$ \\
\hline B: Regression coefficient, SE: Standard error, Cl: Confidence interval
\end{tabular}

\section{Discussion}

RA is associated with reduced bone density, [3], and an increased risk of fragility fractures [5]. The pathophysiology of osteoporosis is complex, with contributions from general risk factors such as age, gender along with disease-specific risk factors such as decreased mobility, corticosteroid use and production of proinflammatory cytokines [22].

This cross sectional study of patients with RA has shown that the overall prevalence of osteoporosis was $26.9 \%$, which is significantly higher than the prevalence of osteoporosis in a gender- and agematched control cohort. These observations are in keeping with previous reports that recorded a prevalence of osteoporosis ranging between $17 \%$ and $32 \%$ in the spine and $15 \%$ and $36 \%$ in the hip of rheumatoid patients [23, 24].

This cross-sectional study examined 93 patients. Similar to previous studies, the current study showed that more women (88\%) suffer from RA. Ikuyama and his colleagues [25] conducted a study involving RA patients. In their study, the prevalence of women was significantly higher (84\% women). Similarly, Kuo et al [26] carried out a nationwide study to examine the incidence and mortality of RA in Taiwan and found that both the incidence and mortality of RA was higher in women than that in men.

In the current study, the average patient age was $46.5 \pm 15.2$ years, which is similar to the average age of patients with RA. Similarly, in a recent study by Sineglazova and his colleagues [27] revealed that the average age of patients with RA was $49 \pm 7.4$ years. In another study, McCoy and his colleagues [28] found that the average age of patients with RA was 55.5 years; thus, RA typically occurs in older patients.

Also, RA factor was found to be positive in $65.6 \%$ of patients. In a study by Suresh [29], RA factor was positive in $70 \%$ of patients suffering from RA; hence, the presence of RA factor aids in the diagnosis of RA. 
The five most common associated comorbidities were HTN (14.0\%) and DM (17.2\%). Al-Bishri and his colleagues 2013 found that associated comorbidities were HTN (36\%), DM (31\%). The higher percentage in his study is due to larger sample size (340 patients)[30]. The number of patients with hypothyroidism and hyperthyroidism were $4.3 \%$. A literature review disclosed a geographical variation of thyroid disease in RA ranging from $0.5 \%$ to $27 \%$ [31].

The current study was trying to explore different factors affecting emergence of osteoporosis in rheumatoid patients. It was focused on inflammatory markers of R.A, steroid use, vitamin D and systemic factors.

We searched an association between the levels of inflammatory markers and osteoporosis, However, in our study, neither of these variables (ESR, CRP, RF and anti- (CP) emerged as independent predictors of bone density in the univariate or logistic regression analysis ( $p \geq 0.5)$.

In contrast, Haugeberg and his colleagues, 2000 displayed that female RA patients showed lower bone mineral density (BMD) values if they are positive for Rheumatoid Factor. they studied females only and correlate with RF solely [23].Also Guler and his colleagues 2008 found that seropositivity for anti-cyclic citrullinated peptide antibody (anti-CCP) and rheumatoid factor (RF) have been shown to be associated with bone loss in RA [26].

However, others failed to find such a relation and concluded that the contribution of RA associated factors like anti-CCP, RF and disease activity in bone mass loss and osteoporosis require longitudinal studies [32, 24].

The current study showed that steroid use was $22.6 \%$ in our study group. logistic regression analysis showed that Steroids intake was a factor increasing the likelihood of having osteoporosis $(95 \% \mathrm{Cl}$ $=3.745$ (0.889-15.773)).

The relationship between steroid use and low BMD is not described evenly between different studied. Van Staa, 2006 [32] found a relationship between corticosteroid use and osteoporosis. Kroot and his colleagues 2001[34] found the use of prednisone was significantly associated with increased bone loss as well. Similarly, Haugeberg [3] showed that one of Predictors of reduced BMD was current use of corticosteroids.

Westhovens et al. [35], Akar et al. [36] and EnGVALl et al. [37] found no influence of glucocorticoid treatment on total "bone mineral density". The authors concluded that it may be due to small sample size. It is possible that better control of RA by steroid use has improved bone mass in these patients or the sample size may have influenced this result.

As regard vitamin $D$, our study group was generally deficient in vitamin $D$ level $(9.1 \pm 3.5 \mathrm{ng} / \mathrm{mL})$. Vitamin D was not significantly different between osteoporotic and none.

Similar to this study, Rossini and his colleagues, 2011 [41] found vitamin D level to be very similar among the erosive and nonerosive RA. Low BMD level was only dependent on parathyroid hormone (PTH) values. Likewise Piao and his colleagues, 2015 did not find any association between vitamin D level and osteoporosis when they evaluated risk factors of osteoporosis in rheumatoid Chinese men [45].

On the contrary, In a systematic review, vitamin D concentration correlated positively with BMD and inversely with the risk of falls [38], These data also observed in a large population of postmenopausal women [39], as well as in the community-dwelling men and women aged at least 20 years who participated to the US NHANES III survey [40]. The difference may be due to large sample size and different age groups in the previous two studies.

With respect to systemic factors, which were underestimated by many studies, age was found to be significantly different between osteoporotic and none ( $p=<0.001)$. This is Similar to what occurs universally. Riggs and Melton, 1986 and Wasnish, 1996 $[42,43]$ showed that BMD has inverse correlation 
with age. Similar results were found by Mobini and his colleagues, 2012 [44], in a study of 121 patients with RA, with age of $55.7 \pm 10.1$ years. The data reported in this study indicated that only the age and body mass index (BMI) were significant associated factors of osteoporosis in RA and the contribution of other factors of osteoporosis including disease activity, disease duration, physical disability, and seropositivity for anti-CCP and RF in the development of osteoporosis was not significant.

As in previous studies [13-16], female gender was significantly prevalent in osteoporotic group. This agrees with HAUSER et al, 2014 who evaluate the clinical predictors of osteoporosis in RA in a cohort and found that women had significantly lower BMD [46].

Regarding comorbidities, diabetes represents $32.0 \%$ of osteoporotic group versus $11.8 \%$ in nonosteoporotic group. Concerning hypertension, osteoporotic group have $28.0 \%$, while none have $8.8 \%$. This study shows significant association between comorbidities, diabetes and hypertension, and presence of osteoporosis. In contrast Piao and his colleagues, 2015 conducted a large-scale, community-based, cross-sectional study to investigate the associations with osteoporosis in rheumatoid arthritics Chinese men and did not show any correlation with diabetes and hypertension [45].

Surprisingly, this study found that serum ionized calcium is significantly different between osteoporotic and none. When we further analyze that in Logistic regression model, it is still found that decreasing serum ionized calcium was a factor increasing the likelihood of having osteoporotic $(95 \% \mathrm{Cl}=$ 0.016 (0.003-0.101)). This result agreed with a single study done to assess the extent of bone loss and the influence of corticosteroid treatment and total body calcium in 63 patients with rheumatoid arthritis. They compared with 40 normal controls. There were significant reductions in mean total body calcium in the group treated with non-steroidal antiinflammatory drugs (5.3\% in men; $6.8 \%$ in women) and greater reductions in the corticosteroid-treated patients [47]. Patients in this study did not have DEXA and they conclude that increased bone loss in patients with rheumatoid arthritis treated with corticosteroids is attributable to drug treatment rather than disease activity.

\section{Abbreviations}

$\mathrm{RA}=$ Rheumatoid Arthritis

Vit $\mathrm{D}=$ Serum $25-\mathrm{OH}$ vitamin $\mathrm{D}$

$E S R=$ erythrocyte sedimentation rate

$\mathrm{CRP}=\mathrm{C}$-reactive protein

$\mathrm{RF}=$ rheumatoid factor

Anti-CCP $=$ anticyclic-citrullinated protein/peptide antibodies

DEXA = Dual-energy X-ray absorptiometry

$\mathrm{DM}=$ Diabetes

$\mathrm{HTN}=$ Hypertension

$\mathrm{PTH}=$ parathyroid hormone

$\mathrm{Cl}=$ Confidence interval

$\mathrm{BMI}=$ body mass index

$\mathrm{BMD}=$ bone mineral density

RA $=$ Rheumatoid Arthritis

ACR-EULAR = American College of Rheumatology-European League against Rheumatism

$\mathrm{HB}=$ hemoglobin level

$\mathrm{CA}=$ Calcium

\section{Authors' contributions}

Sahar Saad conceived the study, helped to recruit the patients. Khalid A AbulSaad articipated in the conception and design of the study. Safaa Hussein Ali contributed to drafting the manuscript. All authors read and approved the final manuscript.

\section{Author details}

Sahar Saad: associate professor of rheumatology. Faculty of medicine, Assiut university.

Saharsaad68@gmail.com 
Khalid A AbulSaad: consultant of geriatric medicine. Geriatrics and Gerontology department, Faculty of Medicine, Ain Shams University, Cairo, Egypt.

Safaa Hussein Ali: consultant of geriatric medicine. Geriatrics and Gerontology department, Faculty of Medicine, Ain Shams University, Cairo, Egypt. bokabokloz@yahoo.com

\section{Acknowledgments}

We acknowledge the study participants for their gracious help.

\section{Competing interests}

No conflict of interest has been declared by the authors.

\section{Disclosure statement}

This paper was supported by Ain Shams University, geriatric department. All authors declare that there is no financial support or relationship that may pose conflicts of interest.

\section{References}

1. Fischer C, Faselis C, Levy J. USMLE Step 2 CK Lecture notes, Internal Medicine. Vol. 9. New York, NY: Kaplan Medical; 2008. pp. 46-50.

2. Miyasaka N. for CHANGE Study Investigators. Clinical investigation in highly disease-affected rheumatoid arthritis patients in Japan with adalimumab applying standard and general evaluation: the CHANGE study. Mod Rheumatol. 2008; 18(3): 252-62

3. Haugeberg G, Uhlig T, Falch JA, Halse JI, Kvien TK. Bone mineral density and frequency of osteoporosis in female patients with rheumatoid arthritis-results from 394 patients in the Oslo County Rheumatoid Arthritis Register. Arthritis Rheum 2000; 43: $522-30$

4. Sinigaglia L, Nervetti A, Mela Q, et al. A multicenter cross sectional study on bone mineral density in rheumatoid arthritis. J Rheumatol 2000; 27: 2582-9.

5. VanStaa TP, Geusens P, Bijlsma JWJ, Leufkens HGM, Cooper C. Clinical assessment of the long-term risk of fracture in patients with rheumatoid arthritis. Arthritis Rheum 2006; 54: 3104-12.

6. Gough AK, Peel NF, Eastell $R$, et al. Excretion of pyridinium crosslinks correlates with disease activity and appendicular bone loss in early rheumatoid arthritis. Ann Rheum Dis 1994; 53: 14-7.
7. Laan RFJM, Vanriel PLCM, Vanerning LJTO, et al. Vertebral osteoporosis in rheumatoid-arthritis patients-effect of low-dose prednisone therapy. Br J Rheumatol 1992; 31: 91-6.

8. Reid IR, Plank LD, Evans MC. Fat mass is an important determinant of whole body bone density in premenopausal women but not in men. J Clin Endocrinol Metab. 1992; 75(3): 779-82.

9. Song GG, Bae SC, Lee YH. Association between vitamin D intake and the risk of rheumatoid arthritis: a meta-analysis. Clin Rheumatol, 31 (2012), pp. 1733-1739.

10. Als OS, Riis B, Christiansen C. Serum concentration of vitamin D metabolites in rheumatoid arthritis. Clin Rheumatol, 6 (1987), pp. 238-243.

11. Sainaghi PP, Bellan M, Carda S, Cerutti C, Sola D, Nerviani $A$, et al. Hypovitaminosis $D$ and response to cholecalciferol supplementation in patients with autoimmune and nonautoimmune rheumatic diseases. Rheumatol Int, 32 (2012), pp. 3365-3372.

12. Cutolo M, Otsa K, Laas K, Yprus M, Lehtme R, Secchi ME, et al. Circannual vitamin $d$ serum levels and disease activity in rheumatoid arthritis: northern versus southern Europe Clin Exp Rheumatol, 24 (2006), pp. 702-704

13. Canalis E, Mazziotti G, Giustina A, Bilezikian JP. Glucocorticoidinduced osteoporosis: pathophysiology and therapy Osteoporos Int, 18 (2007), pp. 1319-1328.

14. Canalis E. Effect of glucocorticoids on type I collagen synthesis, alkaline phosphatase activity, and deoxyribonucleic acid content in cultured rat calvariae Endocrinology, 112 (1983), pp. 931-939.

15. Ito S, Suzuki N, Kato S, Takahashi T, Takagi M. Glucocorticoids induce the differentiation of a mesenchymal progenitor cell line, ROB-C26 into adipocytes and osteoblasts, but fail to induce terminal osteoblast differentiation. Bone, 40 (2007), pp. 84-92.

16. De Nijs RN, Jacobs JW, Bijlsma JW, Lems WF, Laan RF, Houben $\mathrm{HH}$, et al. Prevalence of vertebral deformities and symptomatic vertebral fractures in corticosteroid treated patients with rheumatoid arthritis. Rheumatology, 40 (2001), pp. 1375-1383.

17. Grossman JM, Gordon R, Ranganath VK, Deal C, Caplan L, Chen W, et al. American College of Rheumatology 2010 recommendations for the prevention and treatment of glucocorticoid-induced osteoporosis. Arthritis Care Res, 62 (2010), p. 1515

18. Michaud K, Wolfe F. Comorbidities in rheumatoid arthritis. Best Pract Res Clin Rheumatol.2007; 21(5): 885-906.

19. Linde L, Sørensen J, Østergaard M, Hetland ML. Health-related quality of life of patients with rheumatoid arthritis. Which factors are of significance? Ugeskr Laeger. 2008; 170(10): 855-8.

20. Arnett FC, Edworthy SM, Bloch DA, et al. The American Rheumatism Association 1987 revised criteria for the classification of rheumatoid arthritis. Arthritis Rheum. 1988; 31(3): 315-24.

21. Assessment of fracture risk and its application to screening for postmenopausal osteoporosis. Report of a WHO Study Group. World Health Organ Tech Rep Ser. 1994; 843: 1-129. 
22. Sinigaglia L, Nervetti A, Mela Q, et al. A multicenter cross sectional study on bone mineral density in rheumatoid arthritis. $J$ Rheumatol 2000; 27: 2582-9.

23. Guler H, Turhanoglu AD, Ozer B, Ozer C, Balci A. The relationship between anti-cyclic citrullinated peptide and bone mineral density and radiographic damage in patients with rheumatoid arthritis. Scand J Rheumatol. 2008; 37: 337-42.

24. Habib GS, Haj S. Bone mineral density in patients with early rheumatoid arthritis treated with corticosteroids. Clin Rheumatol. 2005; 24: 129-33.

25. Ikuyama S, Imamura-Takase E, Tokunaga S, Oribe M, Nishimura J. Sixty percent of patients with rheumatoid arthritis in Japan have used dietary supplements or health foods. Mod Rheumatol.2009; 19(3): 253-9.

26. Kuo CF, Luo SF, See LC, Chou IJ, Chang HC, Yu KH. Rheumatoid arthritis prevalence, incidence, and mortality rates: a nationwide population study in Taiwan. Rheumatol Int. 2012; 33(2): 355-60.

27. Sineglazova AV, Kalev OF, Trushin IV, Rostovtsev MV. Special features of coronary artery involvement in women with rheumatoid arthritis. Kardiologiia. 2012; 52(8): 44-7.

28. McCoy SR, Warren RF, Bade HA, 3rd, Ranawat CS, Inglis AE. Total shoulder arthroplasty in rheumatoid arthritis. J Arthroplasty. 1989; 4(2): 105-13

29. Suresh E. Diagnosis of early rheumatoid arthritis: what the nonspecialist needs to know. J R Soc Med.2004; 97(9): 421-4.

30. Al-Bishri J, Attar S, Bassuni N, Al-Nofaiey Y, Qutbuddeen $H$, Al-Harthi S, Subahi S. Comorbidity profile among patients with rheumatoid arthritis and the impact on prescriptions trend. 2013 Apr 4; 6: 11-8. doi: 10.4137/CMAMD.S11481.

31. Cárdenas Roldán J, Amaya-Amaya J, Castellanos-de la Hoz J, et al. Autoimmune thyroid disease in rheumatoid arthritis: a global perspective. Arthritis. 2012; 2012: 864907.

32. Cortet B, Guypt MH, Solau E, et al. Factors imfluencing bone loss in rheumatoid arthritis: a longitudinsl study. Clin Exp Rheumatol. 2000; 18: 683-90.

33. Van Staa TP. The pathogenesis, epidemiology and management of glucocorticoid-induced osteoporosis. Calcif Tissue Int. 2006; 79(3): 129-37.

34. Kroot Ejja, Laan RF, Van Riel PL, Nieuwenhuizen MG, Waal MMC, PC Pasker. Change in bone mineral density in Patients with rheumatoid arthritis during the first decade of disease. Arthritis Rheum. 2001; 44:. 1254-60 [Links]

35. Westhovens R, Nijs J, Taelman V, et al. Body composition in rheumatoid arthritis. Br J Rheumatol.1997; 36: 444-448.

36. Akar S, Sari I, Comlekci A, et al. Body composition in patients with rheumatoid arthritis is not different than healthy subjects. Eur J Rheumatol. 2014; 1: 106-110.

37. Engvall IL, Brismar K, Hafstrom I, et al. Treatment with low-dose prednisolone is associated with altered body composition but no difference in bone mineral density in rheumatoid arthritis patients: a controlled cross-sectional study. Scand J Rheumatol. 2011; 40: 161-168
38. Cranney, T. Horsley, S. O'Donnell, H. Weiler, L. Puil, D. Ooi, et al. Effectiveness and safety of vitamin $D$ in relation to bone health. Evid Rep Technol Assess, 158 (2007), pp. 1-235.

39. Kuchuk NO, Van Schoor NM, Pluijm SM, Chines A, Lips P. Vitamin D status, parathyroid function, bone turnover, and BMD in postmenopausal women with osteoporosis: global perspective. J Bone Miner Res, 24 (2009), pp. 693-701.

40. Bischoff-Ferrari HA, Kiel DP, Dawson-Hughes B, Orav JE, Li R, Spiegelman D., et al. Dietary calcium and serum 25-hydroxyvitamin D status in relation to BMD among U.S. adults. J Bone Miner Res, 24 (2009), pp. 935-942.

41. Rossini, Bagnato G, Frediani B, lagnocco A, La Montagna G, Minisola $G$, et al. Relationship of focal erosions, bone mineral density, and parathyroid hormone in rheumatoid arthritis. Rheumatol, 38 (2011), pp. 997-1002

42. Riggs BL, Melton LJ. Involutional osteoporosis. Engl J Med 1986 N; 314:.. 1676-84

43. Wasnish RD. Epidemiology of osteoporosis. In: MJ favus. Primer on the metabolic bone diseases and disorders of mineral metabolism. 3 rd ed. Chicago: Lippincott-Raven; 1996. p.24951.

44. Mobini M, Kashi Z, Ghobadi farA. Prevalence and associated factors of osteoporosis in female patients with rheumatoid arthritis. Caspian J Intern Med. 2012; 3: 421-4.

45. Piao HH, Zhang KQ, Tang ZH. Association between rheumatoid arthritics and osteoporosis among Chinese men, a community based study. Int J Clin Exp Med. 2015 Sep 15; 8(9): 16592-16598.

46. Hauser B, Riches PL, Wilson JF, Horne AE, Ralston SH. Prevalence and clinical prediction of osteoporosis in a contemporary cohort of patients with rheumatoid arthritis. Rheumatology (Oxford). 2014 Oct; 53(10): 1759-66. doi: 10.1093/rheumatology/keu162.

47. Reid DM, Kennedy NS, Smith MA, Tothill P, Nuki G. Total body calcium in rheumatoid arthritis: effects of disease activity and corticosteroid treatment. Br Med J (Clin Res Ed). 1982 Jul 31; 285(6338): 330-2.

\section{Publish in International Archives of Medicine}

International Archives of Medicine is an open access journal publishing articles encompassing all aspects of medical science and clinical practice. IAM is considered a megajournal with independent sections on all areas of medicine. IAM is a really international journal with authors and board members from all around the world. The journal is widely indexed and classified Q1 in category Medicine. 